\title{
HACIA LA CONFORMACIÓN DE UN TRIBUNAL PENAL INTERNACIONAL. EVOLUCIÓN HISTÓRICA Y DESAFÍOS FUTUROS
}

\author{
Raúl Carnevali Rodríguez ${ }^{2}$ (D)
}

\author{
Me celebro y de mi mismo canto, \\ Y lo que yo me atribuyo lú debes \\ Atribuirtelo, \\ Pues cada átomo mio también te \\ Pertenece a ti. \\ Canto de mí mismo \\ Walt Whitman
}

SUMARIO: I.- Introducción. II.- Qué se protege a través del Derecho Penal Internacional. II.- Hacia la instauración del Tribunal Penal Internacional. Breve reseña histórica. a.- Antecedentes previos a la Guerra de 1914. b.- Entre las dos conflagraciones mundiales. c:Desde Nuremberg hasta la Conferencia de Roma de 1998. Conformación del Tribunal Penal Internacional. IV.-Tareas pendientes para el Tribunal Penal Internacional. V.- Conclusiones finales.

\section{INTRODUCCIÓN}

1. Cuando a fines del s. XVIII las viejas instituciones europeas se vieron remecidas por la consolidación en Francia de los ideales liberales que motivaron la revolución, no pocos creyeron que se acercaba la época en que la libertad, la igualdad y la fraternidad se harían realidad y que se extenderían por todo el continente. Se respiraba pues, un aire de franco optimismo, en que la paz entre los pueblos sería permanente. Es en este contexto en que Kant escribe su obra La pa\% perpetua - 1795_ ${ }^{3}$. Alli el insigne pensador alemán, a través de una serie de propuestas, pone toda su esperanza en que la relación entre las naciones se funden en el derecho y la moral ${ }^{+}$, resaltando que la paz jamás se logrará si ésta se basa sólo en tratados de paz, pues se tratan únicamente de armisticios, en que la voluntad de

\footnotetext{
${ }^{1}$ Este trabajo forma parte del proyecto FONDECYT' regular No 1010187 titulado "Jurisdicción extraterritorial y Derecho penal internacional".

2 3

3 Kint, La paz perpetma, (l'rad. I. Rivera Pastor), Madrid, 2000, passim.

'Cabe consiguar que otros autores del siglo XVIII también participaron de este propósito. Asi, entre otros, Montesquieu, Rousseau y Saint-Pierre. Al respecto, cfr. Truyor. y Serra, Hisforia de La Filosofía y del Dencho, 1I, Madrid, 1975, p. 220, p. 269-270; Bi-RoUD/WFyDERT, I.'Alenenir del'turope, Paris, 1997. p. 41-46.
} 
un Estado se impone a la de otro. La paz "perpetua" únicamente es posible si se alcanza a través de un pacto entre los pueblos. Lamentablemente, han transcurrido algo más de dos siglos de aquellas palabras y parece ser que todavía se sostiene la idea de que el orden internacional y la relación entre las naciones puede perdurar en la medida en que las políticas militares jueguen un rol predominante, lo que evidentemente hace que el "resguardo" de ese orden recaiga de forma preponderante en las grandes potencias, con los riesgos que ello conlleva. Esto es, que quienes tengan la fuerza impongan los términos, prescindiendo o limitando la aplicación del Derecho en sus actuaciones. Lo recién expuesto, también es plenamente aplicable en caso de conflictos internos, en que los vencedores serán los que determinarán las bases en las que habrán de moverse los vencidos. En definitiva, no es mucho lo que se ha avanzado desde el s. XVIII, en cuanto a que la paz internacional todavía se sostiene esencialmente — siguiendo a Kant- a través de armisticios.

2. Con lo expuesto no quiero decir que no ha habido progresos en la esfera del Derecho internacional y en concreto del Derecho penal internacional - como se verá infra-, pero es justo afirmar que la vía jurídica todavía genera ciertas dudas en la comunidad internacional, sobre todo de las grandes potencias, en la medida en que la instauración de un recurso punitivo internacional pudiera afectar sus posiciones preponderantes en el orden mundial. Sin embargo, a pesar de la oposición de algunos Estados, el que hayan participado 160 naciones en la Conferencia de Roma y que 120 hayan votado a favor del Estatuto - julio de 1998 - y que hasta la fecha — agosto de 2003 - 91 Estados lo hayan ratificado es una clara manifestación de que la voluntad de la comunidad internacional se dirige en una sola dirección: la protección de los derechos fundamentales se puede garantizar eficazmente a través de la justicia.

3. Ahora bien, que la comunidad internacional haya tomado conciencia de lo anterior no ha sido fácil. Precisamente, en las páginas que siguen, se pretende ilustrar acerca del largo camino que la humanidad ha tenido que recorrer para llegar a internalizar la idea de que la estabilidad social se alcanza si hay justicia. A continuación, me detendré a examinar los problemas relativos al ius puniendi

\footnotetext{
${ }^{5}$ Kunt, La pavin, p. 111 , p. 159

6

${ }^{6}$ Paradigmática resulta, en este sentido, fa posición del senador norteamericano Jesse Helms para rechazar el Estatuto de Roma. Alli argumenta que la Corte someterá a juicio la política de seguridad de los liEUU, entre cuyos actos se cncuentra la invasión a Granada, Panami o el bombardeo a Tripoli, en los que no se solicitó la autorización de la ONU. 1 id. Financial Timer, de 31 de julio de 1998 (rcproducido en www.derechos.org/nizkor/impu/tpi/helms.html). Para conocer la posición de EEUU frente al establecimiento de un Tribunal penal internacional, cfr. SCHFFFER, "The United States and the International Criminal Court", en: American Journal of International Lan, No 3, 1999, p. 12 y ss.; WEDGWOOD, "The International Criminal Court: an American View", en: Luropean Joternal of International I am, N" 10, 1999 , p. 93 y ss.; HAINER/BOON/ROBFSAME/TIUSTON, "A response to the American View as presented by Ruth Wedgwood", en: Eumpean Journal of International Law, N" 10, 1999, p. 109 y ss;; DAviD, "Grotius repudiated: the American objetions to the International Criminal Court and the commitment to International Law", cn: Michigan Journal of International I asy, 1999, p. 337 y ss.
} 
supranacional, que van indefectiblemente unidos al de la soberanía estatal y su limitación, para luego finalizar con el estudio de algunos de los aspectos más esenciales del Estatuto de Roma.

\section{QUÉ SE PROTEGE A TRAVÉS DEL DERECHO PENAL INTERNACIONAL}

1. Antes de comenzar a desarrollar los puntos señalados precedentemente, es indispensable precisar cuál es el objeto de tutela en este campo, qué es lo que se pretende amparar. Si bien el término "Derecho penal internacional" ha sido objeto de cuestionamientos", he preferido mantenerlo dado que éste ha sido el que tradicionalmente se ha empleado para comprender todos aquellos actos que suponen una clara vulneración de los derechos fundamentales, en cuanto bienes jurídicos individuales, y que pueden poner en peligro la paz internacional ${ }^{8}$. Empero, si bien lo recién expuesto comprende de forma amplia el objeto que se analiza, ciertas precisiones son necesarias, si no se quiere caer en una peligrosa expansión de la herramienta punitiva. En efecto, si hablamos sólo de protección de los derechos fundamentales, ello podría también abarcar $v$. gr. los atentados contra el medio ambiente, si estos ponen en serio riesgo la vida y la salud de un grupo de personas. $Y$ es que, como lo ha manifestado Ragués i Vallès, parece ser que tarde o temprano el Derecho penal internacional se ampliará a otros intereses, más allá de lo que es la vulneración de los derechos fundamentales más básicos. Es ante este probable escenario que se hace urgente precisar qué intereses han de motivar, de manera particular, la intervención del poder punitivo internacional y cómo se articulará esta intervención".

\footnotetext{
7 Al repecto, cfr. JIMĖNeZ DE ASÚA, Trutado de Derebo penal, T. II, Buenos Aires, 1950, p. 621 y ss.; Gin. Git, Dencbo penal internaciontal, Madrid, 1999, p. 23 y ss:; para Clerizzo MIR, Carso de Derecho penal español, 1, PG, $5^{\circ}$ ed., Madrid, 1996, p. 208, el nombre de Derecho penal internacional deberia reservarse para la legislación penal internacional que emana de la comunidad internacional y a la que están sometidos directamente los ciudadanos; IIFGLERA GUINERA, "Ia Parte General del Derecho penal contenida en el Estatuto de Roma de ha Corte penal internacional", en: Hacia una justiciu 8 internusional, Madrid, 2000 , p. 603.

$\mathrm{Al}$ respecto, cfr. BAssioun, "The proscribing Function of International Criminal Law in the Processes of Inturnational Potcetion of Human Rights", en: Festschrift fir Hans Heinrich Jescheck sim 70 Geburstag, Berlin, 1985, p. 1453 y ss.

9. Cfr. Ruguŕs I VAlLís, "El Tribunal penal internacional. La última gran institución del siglo XX (I)", La Ley, 17 de abril de 2001 , p. 2 ; si bien, no corresponde tratarlo aquí, pero tengo mi serias reservas sobre la intervención que ha de tener el Derecho penal en materia medio ambiental, por cuanto se pueden vulnerar principios esenciales, como el de intervención minima. Al respecto, cfr. CARNILvAl, RODRiGUEz, Derecha penal y Derecto sancionador de la Unión Eurmpea, Granada, 2001, p. 398 y ss, en especial p. 405-409; por su parte, MAIER, "Derecho penal internacional, crimenes contra la humanidad, extraterritorialidad de la ley penal aplicable y competencia de juzgamiento", en: Cantra la imprunidad. Simpasio cantra la imptunidad y en defensa de las derechas humanos, Barcelona, 1998, p. 146, subraya el riesgo de que un Derecho penal internacional siga una senda similar a los sistema penales nacionales en cuanto a su extensión, y que termine calificando como delitos contra la humanidad el trífico ilícito de drogas y un concepto tan oscuro como es el de "criminalidad organizada".
} 
2. Ambos ${ }^{10}$ ante la pregunta de cuáles son las violaciones a los derechos humanos que debieran comprenderse en esta esfera, es claro en afirmar, sobre la base de los bienes jurídicos clásicos — así, la vida, la integridad corporal, la libertad individual-, que el análisis debe limitarse a los derechos civiles y políticos en el sentido del Pacto Internacional de derechos civiles y Políticos - llamados derechos de primera generación - ${ }^{11}$ y de otros acuerdos internacionales ${ }^{12}$, no debiendo incluirse los derechos económicos, sociales y culturales - derechos de segunda generación- ${ }^{13}$, ni menos aquellos que permiten proteger intereses de carácter universal, como son, entre otros, el derecho al desarrollo, el medio ambiente - de tercera generación-. Lo anterior en razón de que estos dos últimos no tienen el reconocimiento de los primeros y aún no existe la convicción sobre la necesidad de emplear el instrumento penal ${ }^{14}$.

3. Es por ello que tenemos que entender que en esta esfera la finalidad tuitiva son determinados bienes jurídicos de carácter individual, en tanto su afectación pone en peligro el orden internacional ${ }^{15}$. Dicha relación es fundamental de establecer a fin de evitar que delitos que indudablemente lesionan derechos humanos esenciales — así, la vida y la salud- puedan ser comprendidos dentro del ius puniendi internacional. Ahora bien, para estos efectos, cuando se habla de orden internacional, éste debe entenderse desde la perspectiva de la comunidad internacional, esto es, como aquel conjunto universal de seres humanos que cuentan con intereses fundamentales que le son propios ${ }^{16}$. Existen pues, determinados bienes que le pertenecen a la humanidad toda y que resultan esenciales para su desarrollo social. Se aprecia en consecuencia, que también en el orden internacional el individuo en cuanto tal es reconocido y por tanto, digno de recibir protección. Por tanto, para este efecto constituirán delitos internacionales en la medida en que los actos que afecten a determinados bienes jurídicos individuales

\footnotetext{
10) Ambos, Impunidad y Denecho penal incernucional, Buenos Aires, 1999, p. 44-45.

Pacto Internacional de Derechos civiles y Políticos, adoptado por la Asamblea Gencral de las Naciones Unidas a 16 de diciembre de 1966.

12

Así, entre otros, las Convenciones de Ginebra de 1949 y sus protocolos adicionales, la Convención sobre el genocidio de 1948 y la Convención sobre la tortura de 1984. I id. AMBOS, Imprenidad..., p. 46-47.

13

Entendiendo éstos conforme al Pacto Internacional de derechos económicos, sociales y culturales. Adoptado por la Asamblea General de las Naciones Unidas el 16 de diciembre de 1966 y ratificado por Chile el 10 de febrero de 1972.

14

Para AMBOS, Impunidad..., p. 45, los derechos, tanto de primera como de segunda generación constituyen una unidad conceptual, paes se requicren mutuamente para su pleno desarrollo.

15

Gabe cunsignar que el propio Estatuto de Roma en su Art. 5. I señala que la competencia de la Corte se limitarí a los crímenes más graves de traicendencia para la commuidad intemacional. Al respecto, BURNO $A$ RÚs, "Perspectivas de la teoría general del delito en el Estatuto de la Corte penal internacional de 17 de julio de 1998", en: Creacioin de ana jurrisdicaón pemul inlernacional, Colección Escuela diplomática $\mathrm{N}^{\circ} 4$, Madrid, 20)( , p. 122, hace presente que el denominador común de los delitos alli contemplados se hallarian en el peligro para la supervivencia de grandes grupos de personas.

16. Tal como expone Gil. Gil., Derecho penat..., p. 34, cuando se habla de orden internacional, éste se concibe desde una doble vertiente, a saber: la comunidad de estados y la comunidad internacional.
} 
sean de tal relevancia que supongan un serio riesgo el orden internacional ${ }^{17}$. Lo anterior supone pues, hacer una doble valoración, por una parte, deben tratarse de bienes juridicos individuales que sean fundamentales para el mantenimiento de todo sistema social y por otra, que su transgresión sea de tal dimensión que ponen en peligro la estabilidad internacional. Este último criterio es fundamental para poder distinguir un acto aislado - en el que el aparato represivo nacional tiene las herramientas para mantener la estabilidad social- de aquellas violaciones sistemáticas en las que el Estado nada hace, ya sea porque asume un papel activo en su realización o al menos los tolera, o porque el sistema penal nacional ha desaparecido. No cabe duda que frente a este último supuesto, los conflictos adquieren una relevancia internacional, pues, a mi modo de ver, se trata de crímenes que conciernen a la comunidad toda, pues se están afectando las bases mínimas de toda convivencia. No sólo existe el deber sino también el derecho de juzgar, más aún si los Estados llamados a actuar no lo hacen. Al respecto, no hay que olvidar que el carácter subsidiario - ultima ratio- del Derecho penal internacional frente a los derechos nacionales ${ }^{18}$ es un reflejo de que, en definitiva, la titularidad del ius puniendi en esta esfera también recae en la propia comunidad internacional, por cuanto se está frente a actos que afectan a bienes que pertenecen a la humanidad, al ser básicos para su supervivencia. Si entendemos, en general, que dentro de un Estado la precisión de los bienes jurídicos sobre los cuales ha de recaer la tuición penal le corresponde a la propia sociedad nacional, siendo ésta la que ha decidido además, que el ejercicio punitivo debe recaer en manos de sus propias autoridades, estimo que no existen dificultades para considerar que en un determinado contexto, la misma sociedad - ya no nacional sino internacional - resuelva, como titular de ciertos bienes jurídicos de carácter internacional, crear una instancia distinta a las internas para que sea ésta la que ejerza la actividad punitiva —asi, el Tribunal penal internacional-. Es evidente que lo expuesto es un reflejo de los cambios que se han ido generando por la globalización ${ }^{19}$, que con su avance pone en entredicho y

\footnotetext{
17

7 Criterios como Tracendencia para la Commidad Internacional en sa conjunto y Gravedad son importantes para comprender la incorporación de determinados declios en el Estatuto de Roma. Cfr. L.IROL A DFI.cindo, "La competencia material de la Corte Penal internacional. La relación con el proyecto de Código de Crimenes contra la Paz y la Seguridad de la

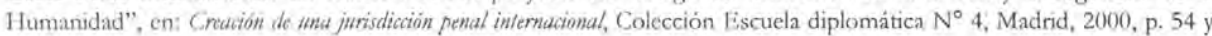
ss.

${ }^{18}$ Cfr. GIt. Gill, Derebia penal..., p. 38-39.

19. Personalmente el fenómeno de la globalización, tal como hơ se está desarrollando, me merece serios reparos, no sólo por las enormes brechas entre las economias ricas y pobres que se estän produciendo, sino por la peligrosa crosión que está teniendo fugar sobre las bases misma de la convivencia social. En efecto, es cada vez más notorio la creciente injèrencia de los grandes grupos económicos en la toma de decisiones, lo que puede convertir a la autoridad pública en un mero ejecutor de las determinaciones que tomen aquéllas. De seguir asi, la democracia, como sistema de gobiemo, sc irá degradando, pues la participación del ciudadano sóló constituira una mera formalidad, pero carecerá de todo contenido. Sin embargo, de la globalización es posible resaltar $\rightarrow$ y precisamente su profundización puede revertir lo recién expuesto- la cada vez mayor conciencia y sensibilidad que se observa en la colectividad frente a cicrtos actos o situaciones a los que la propia sociedad se puede ver expuesta. Ya no somos indiferentes frente a lo que le acontece a otros. Basta apreciar, por cjemplo, las campañas de ayuda para países que se ven enfrentados a carástrofes naturales 0 , perr ntra parte, las demandas de castigo cuando se han transgredido los derechos humanos más esenciales. Respecto de
} 
desestructura el principio de territorialidad y con ello el monopolio estatal del ius puniendl ${ }^{20}$.

4. Ahora bien, el que intervengan primeramente los Estados nacionales en el juzgamiento de determinados delitos internacionales, se puede explicar fundamentalmente por razones prácticas, por cuanto se pueden reunir más fácilmente las pruebas, así como también, las penas pueden tener una mayor eficacia preventivo general. Empero, si los sistemas penales nacionales se muestran ineficaces o incluso, si su intervención puede resultar contraproducente desde una perspectiva preventivo general -asi, amnistías o indultos otorgados arbitrariamente- resulta legítimo recurrir a las instancias punitivas internacionales. En todo caso, que así sea ya no constituye ninguna novedad, toda vez que de conformidad con el Capítulo VII de la Carta de las Naciones Unidas, el Consejo de Seguridad ha estimado que dentro de sus facultades está el tomar medidas para el mantenimiento de la paz y, entre ellas, se incluirian la conformación de Tribunales penales internacionales ${ }^{21}$. Por tanto, ya se admite la posibilidad de que Tribunales distintos a los nacionales puedan juzgar delitos que hayan sido cometidos en sus territorios, incluso con prioridad sobre las jurisdicciones internas. A mayor abundamiento, la Convención para la prevención y la sanción del delito de genocidio de $1948^{22}$, en su Art. VI, dispone que es posible la conformación de una Corte penal internacional ${ }^{23}$.

\section{HACIA LA INSTAURACIÓN DEL TRIBUNAL PENAL INTERNACIONAL. BREVE RESEÑA HISTÓRICA}

\section{a) Antecedentes previos a la Guerra de 1914}

1. Si bien los primeros procesos dirigidos a instaurar Tribunales para juzgar crímenes de carácter internacional comienzan a desarrollarse claramente a partir de los primeros decenios del siglo XX, no es menos cierto que la humanidad ha sido

esto último, es indudable que fue la presión de la "opinión pública", a través de las ONG, lo que determinó de manera importante la instauración del Tribunal penal internacional. Qué duda cabe que una sociedad informada cs esencial para profundizar la democracia, de ahi que debe observarse con mucho cuidado el interés, cada vez menos velado, de los grupos de poder por los medios de comunicación.

201

Como claramente se manifiesta con la Unión Europea, cfr., por todos, CARNevali Rodríguez, Derecho penal..., p. 247 y ss.; Precisamente, este fue uno de los puntos más discutidos durante la Conferencia de Roma, pues los Estados no participantes no apreciaban con bucnos ojos que se les limitarn sus potestades punitivas, cfr. JFSCHECK, "El Tribunal Penal Internacional", (trad. Pifarré de Moner), Rerista Penul, No 8, 2001, p. 53

Como de hecho ha ocurndo, con la conformaciòn de los Tribunales internacionales para la exYugoslavia y Ruanda.

23

Artículo VT: "Las personas acusadas de genocidio o de uno cualquiera de los actos enumerados en el articulo III, serán juzgadas por un tribunal competente del Estado en cuyo territorio el acto fue cometido, o ante la corte penal internacional que sea competente respecto a aquellas de las Partes contratantes que hayan reconocido su jurisdicción". 
testigo en épocas pretéritas de experiencias similares. Aun cuando éstas presentan particularidades que las distinguen, sobre todo en lo que se refiere a la falta de instancias estructuradas y a un escaso nivel garantístico, no por ello no son merecedoras de ocupar un lugar en la historia.

2. Parece ser que el primer juicio respecto de lo que pueden calificarse como crímenes de guerra tuvo lugar en 1474 , en contra de Peter von Hagenbach ${ }^{24}$. El fundamento de la imputación estaría dado por la violación de las leyes de Dios y de los hombres que se habrian cometido durante el sitio de Breisach - Alto Rin-. Es del caso, que von Hagenbach actuando bajo las órdenes de Carlos el Temerario, Duque de Borgona, habría cometido una serie de actos violentos en contra de la población civil, tales como asesinatos, violaciones, confiscaciones de tierra, con el propósito de alcanzar el total sometimiento de la población. En 1476 fue capturado por el Archiduque de Austria, ordenando éste la conformación de un tribunal integrado por 28 jueces de la coalición vencedora, la que estaba compuesta por varios Estados y ciudades - lo que le confirió un carácter internacional-. La defensa argumentó que von Hagenbach actuó cumpliendo órdenes del Duque de Borgoña, las que no se podían cuestionar. En definitiva, se sentenció que von Hagenbach al no haber prevenido los actos que se cometieron, pues se trataba de territorios ocupados, infringió las leyes de Dios y de los Hombres, ordenándose su ejecución.

3. También es preciso destacar los trabajos de Gustave Moynier, uno de los fundadores del Comité Internacional de la Cruz Roja, quien planteó en 1872 la necesidad de establecer un Tribunal internacional permanente para juzgar las violaciones a la Convención de Ginebra de 1864 — sobre el trato a los militares heridos en campaña- Dicha propuesta, que estuvo motivada de manera importante por los excesos cometidos durante la guerra francoprusiana, no tuvo mayor acogida ${ }^{25}$.

\section{b) Entre las dos conflagraciones mundiales}

1. No es sino a partir del fin de la Primera Guerra Mundial cuando se comienza seriamente a trabajar en un Estatuto que permita juzgar crímenes de carácter internacional $^{26}$. Es así, que en 1919 el Tratado de Versalles dispuso, en su

\footnotetext{
24

Cfr. GRr:PP, "Ia evolución de la responsabilidad penal individual bajo el Derecho internacional", en: swwwicrcorg/spa.; Hat., "La primens propuesta de creación de un Tribunal penal internacional permanente", en: 25 Renista Internacional de la Grur. Roja, No 145, 1998, p. 64; KITTICHAISAREE, International criminal lan, New York, 2001, p. 14.

${ }^{25}$ Cfr., con detalle, HAL1.., "I.a primera propuesta...", p. 63 y ss.; asimismo, PFANNER, "Institución de un Tribunal penal internacional permanente", en: Rerista Inlernaciozal de Le Cniz Roju, No 145, 1998, p. 23.

26

Es preciso eonsignar que en 1899 y 1907 tienen lugar las Convenciones de La Ilaya, en las que además de disponer sobre las leyes y costumbres de guerna, tambièn se establecieron mecanismos para resolver pacificamente las controversias a través de tribunales arbitrales. 1id. http://www nca-cpalorg/PI)1/1899SPA.pdf y http://www.pca-cpa.org/PI)I:/1907SPA.pdf. Interesante es hacer notar que en la guerra chino-japonesa de 1895 se aplicaron principios y tendencias en el trato de los combatientes y de los neutrales que luego sirvieron de base
} 
Art. 227, el establecimiento de un Tribunal especial para juzgar al emperador Guillermo $\mathrm{II}^{27}$. Si bien se trataba de un cuerpo judicial, de carácter ad hoc, integrado por las fuerzas vencedoras, ya es posible apreciar el interés cierto de no tolerar determinados comportamientos, aunque se referían esencialmente a las leyes y costumbres de la guerra. Como es sabido, este Tribunal no pudo enjuiciar al Kaiser por la negativa de los Países Bajos - nación en donde se encontraba- a extraditarlo, así como tampoco a otros importantes dirigentes alemanes. Si bien el Tribunal imperial (Reichsgericht) juzgó crímenes de guerra cometidos por alemanes, tuvo escasa repercusión y fue más bien simbólico ${ }^{28}$. Recién a mediados de la década del treinta fue cuando se planteó otro intento serio por establecer un Tribunal internacional ${ }^{29}$. En efecto, a raíz del asesinato del Rey Alejandro de Yugoslavia y del Ministro de Asunto Exteriores francés en 1934, Francia presentó a la Sociedad de las Naciones una iniciativa para juzgar los delitos terroristas. Pues bien, en 1937 se firmó el Convenio para la represión y prevención del terrorismo ${ }^{30}$, cuyo juzgamiento debía corresponder a una Corte penal internacional. Sin embargo, ésta nunca se constituyó, pues el Convenio sólo fue firmado por trece estados por lo que jamás entró en vigencia. Además, los aires nacionalistas que en ese momento se respiraban en Europa impedian cualquier intento en este sentido ${ }^{31}$.

\section{c) Desde Nuremberg hasta la Conferencia de Roma de 1998}

1. Al finalizar la Segunda Guerra Mundial y haciendo efectivo los compromisos expuestos en la Declaración de Moscú de 1 de noviembre de $1943^{32}$,

para los trabajos que se llevaron a cabo en La Haya en 1899. Cfr. Gonzilfz HoNTORIA, "Historia politica y líncas generales de los Estados asiáticos y africanos que cran independientes en 1914", cn: ONCKEN (Dir), Hisforia Uniteral, 'I". XI.V, Barcelona, 1922, p. 70 y ss.

27

Art. 227: "Las potencias aliadas acusan públicamente a Guillermo de I lohenzollern, por falta suprema contra la moral internacional y la autoridad sagrada de los tratados"

28

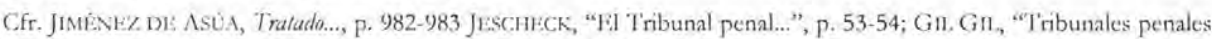
internacionales", en: Revislu de Deretho penal y Criminologia, $\mathrm{N}^{\circ}$ extraordinario $1^{\circ}, 2000$, p. 36-37; KITICHAISARzE, International..., p. 15; 1 IIGURRA Guimeri., "El Iistatuto de la Corte Penal Internacional", en: Actialidal penal, $\mathrm{N}^{\circ} 2,2000$ 1, p. 31; SALMON GARATE/GARCIA SAAVLDRA, "Ios tribunales internacionales que juzgan individuos: el caso de los tribunales ad-hoc para la ex-Yugoslavia y Ruanda y el 'Tribunal Penal Internacional como manifestaciones institucionales 29) de la subjetividad internacional del ser humano", en: www.cajpe.org.pe/guia/artic1.htm.

Es preciso destacar que en 1926, durante el Primer Congreso internacional de Derecho penal celcbrado en Bruselas, se planteó la necesidad de establecer un Tribunal permanente de Justicia internacional con competencia represiva, en el que no sólo se determinara la responsabilidad de los Estados sino que también conociera de las responsabilidades que le cabe a los individuos respecto a los delitos de agresión, así como a toda violación a las leyes internacionales, tanto en tiempos de guerra como de paz. $\mathrm{Al}$ respecto, cfr. JiMÉNEZ DE AsÚ.A, Tratado..., p. 955-956.

M1)

Cabe destacar que a principios del siglo XX el movimiento anarquista generó una importante discusión, tanto teórica como politica acerca de si podían o no calificarse como terroristas. Cfr. MANZINI, Tratado de Derecho penal, T'. I, (trad. Sentis Melendo), Buenos Nires, 1948, p. 567-569

31

32

Én él se acordó enjuiciar a los principales criminales de guerra cuyos delitos no lenian loculizaciön gengráfica particular, los que se castigarian por decisión conjunta de los Gobiernos aliados. En consecuencia, no comprendia aquellos casos en que los delitos se hubieran perpetrado en un lugar determinado. Cfr. JiméNEZ DE ASÙ, "Un comentario a la anunciada 
en el que las potencias aliadas - EEUU, Francia, Reino Unido, Unión Soviéticase comprometían a juzgar a los principales criminales de guerra, se aprobó el Estatuto de Londres de 8 de agosto de 1945 por el que se instauraba un Tribunal Militar Internacional ${ }^{33}$. Precisamente, este cuerpo normativo es el que sirvió de fundamento para llevar a cabo los procesos de Nuremberg, en los cuales se enjuició a los "principales criminales de guerra de los países europeos del Eje" (Art. 6 del Estatuto de Londres) — se juzgó a los principales jerarcas nazis ${ }^{34}$ - La jurisdicción ratione materiae del Tribunal decía relación a los crímenes contra la paz, en el que se comprendía la ejecución de una guerra de agresión o de una guerra en violación de tratados internacionales; de guerra, referido a las violaciones de las leyes y de las costumbres de la guerra; y contra la humanidad, en el que se abarcaban, entre otros actos, los asesinatos, exterminación contra la población civil antes o durante la guerra, persecuciones por motivos políticos, raciales o religiosos-Art. 6- Cabe hacer presente que el Art. 10 disponía el caso de que una organización o grupo fuera declarado criminal por el Tribunal —así ocurrió, por ejemplo, con las SS, SA y los altos dirigentes del partido nazi-. De esta forma se dictaron condenas sobre la única base de haber sido miembro de alguna de estas agrupaciones.

2. Sin entrar a un análisis pormenorizado de este juicio, del que existe por lo demás abundante bibliografia ${ }^{35}$, quisiera destacar de este proceso su alto significado político y las repercusiones que en el orden jurídico se generaron. No cabe duda que la comunidad internacional frente a estos atroces acontecimientos comienza a tomar conciencia sobre la real necesidad de que los derechos más esenciales de las personas deben ser resguardados, es así como, a partir de la segunda mitad del siglo $\mathrm{XX}$, se va desarrollando en este sentido una sostenida tarea normativa. Basta citar la Declaración Universal de Derechos Humanos de 1948, la Convención para la prevención y la sanción del delito de genocidio de 1948, los Convenios de Ginebra de 1949 y el Convenio Europeo para la protección de los Derechos Humanos y Libertades Fundamentales de $1950^{36}$. Por otra parte, el proceso en comento dejó en

acción penal internacional", en: Rerista de Ciencias Penales (Chile), X-XII 1944, p. 330 y ss., quien antes de la instauración de la Corte de Nuremberg reflexiona sobre la inutilidad de los tribunales internacionales frente a esta clase de conflictos, siendo más bien partidario de medidas políticas, incluso de las más radicales.

3.

Vid. el texto del Estatuto de Londres en Jiménez DE Ast́s, Trutado..., p. 1010 y ss. Cabe hacer notar que para evitar que los futuros imputados pudicran buscar refugio en paises americanos, se celebró en México el 6 de marzo de 1945 la "Conferencia Interamericana sobre problemas de la guerra y de la paz". K id. parte de las recomendaciones en JiMÊNEz Dif istił, Tralado..., p. 1018 y ss.

34

La sentencia de 1 de octubre de 1946 impuso 12 penas de muerte a través de la horca - Göering (se suicidó antes), Bormann (juzgado en rebeldia), von Ribbentrop, Keitel, Kaltenbrunner, Rosemberg, Frank, Frick, Streicher, Sauckel, Jodt, Seyss-Inquart - Asimismo, se determinaron penas privativas de libertad, tanto perpetuas - Hess, Raeder y Funk (estos últimos salieron en 1957) - como temporales - Sperr, Dönitz, von Schirach, Neurath-. Fueron absueltos von Papen, Fritzsche, Schacht, Heydecker y Leeb.

35 C.fr. entre otros, JIMENEZ DE ASÚA, Tratado..., p. 999 y ss.

36

El trabajo que ha realizado el Tribunal de Derecho Humanos de Estrasburgo ha sido fundamental para eletrar el nivel garantistico de los paises que forman parte del Conscjo de Europa. Además, el Tratado de la Unión Europea señala en el Art. 6 que los derechos fundamentales se deberán respetar tal y como se garantizan en dicho Convenio. 
claro que determinados crímenes tienen un carácter internacional y que respecto de los cuales es posible su enjuiciamiento a través de una instancia internacional, independiente del cargo que ocupen a nivel estatal ${ }^{37}$. Es cierto, que el juicio mismo merece serios reparos, pues se vulneraron principios esenciales como el de legalidad -no se describian expresamente las conductas típicas y se aplicaban retroactivamente, además las penas no se precisaban ${ }^{38}$ - y el de la responsabilidad penal individual, amén de su cuestionable carácter internacional, pues sólo formaban parte del Tribunal las potencias vencedoras, lo que restaba todo viso de imparcialidad ${ }^{39}$ — críticas similares pueden hacerse al Tribunal Militar Internacional del Extremo Oriente que se constituyó en Tokio ${ }^{41}$ - Sin embargo, a pesar de estas deficiencias, las resoluciones adoptadas en Nuremberg fueron aprobadas por la Asamblea General de las Naciones Unidas el 11 de diciembre de 1946, en la que además se decidió recoger los principios que allí se aplicaron para la elaboración de un Código penal internacional, iniciándose así los trabajos para la instauración de un Tribunal penal internacional. ${ }^{+1}$

\footnotetext{
37 En estos términos, Jescheck, "El Tribunal penal...", p. 54

38

Con detalle, GIL GiL, Dercho penal.., p. 66 y ss.; JIMENEZ DE ASÚA, Tnatado..., p. 1032 y ss. Empero, no faltaron voces sosteniendo que no se habia vulnerado el principios mallum crimen nulla pacha sine lege, pues aun cuando la incriminación se halla formulado ex post factn los hechos delictivos ya se habían desarrollado con el tiempo, por lo que es posible estimarlos como crimenes internacionales. Es asi, que la guerra de agresión se desprendía del Pacto de la Sociedad de las Naciones y del Pacto Briand-Kellog de 1928, al que se habian adherido gran parte de la comunidad internacional, aunque las sanciones sólo se dirigian a los Estados. Todo ello sin perjuicio de las sanciones ya contempladas en el Tratado de Versalles. Fin lo que respecta a las conductas contrarias las leyes de la guerra, la ilicitud de éstas cmanaba de las Convenciones de La Haya de 1899 y 1907 y de Ginebra de 1929, a pesar de que no contenía delitos. Por último, se argumentaba que muchas de estas conductas se hallaban en los ordenamientos penales internos alemanes y japoneses. Cfr. asimismo, Cerezo MIR, Carso..., I, p. 212; RAgues I VAlu.és, "El Tribunal penal internacional...", (I), p. 2; cuestionamientos similares se presentaron en el caso Eichmann, quien fue juggado por tribunales israclíes por delitos que fueron comeridos no sólo fuera de Israel, sino cuando ese Estados ni siquiera existia, cfr. FAWCETT; "The Eichmann case", en: British Yearbook of Internacional Lam, T. XXXVIII, 1962, p. 181 y ss.; GREEN, "The maxim mullum crimen sine lege and the Eichmann 'Trial", en: British Yearbook of International Law, T, XXXVIII, 1962, p. 457 y ss.; CARNEGIF, "Jurisdiction over violations of laws and customs of war", en: British Yearbonk of International I aw, T. XXXIX, 1963, p. 412 y ss.

3)

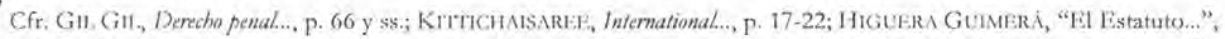
p. 33, quien expone que entre los jerareas vencedores no existia un consenso sobre el destino de los derrotados. Stalin cra de la idea de fusilarlos inmediatamente, Churchill no aceptaba la idea de que los vencedores fueran los juzgadores y De Gaulle estimaba que cada pais debín resolver los delitos que se hubieran cometido en sus territorios; GimeNO SENDRA, "I a experiencia de los 'juicios de Nuremberg' y la necesidad de crear el Tribunal penal internacional", en $I_{\text {a }} I_{\text {sy }}$, 1998-1, p. 1766 y ss.; JeSCHECK, "El 'T ribunal penal...", p. 54.

Los procesos de trokio - Corte establecida por carta de 19 de enero de 1946-, si bien no tuvieron la repercusión mediática que los de Nuremberg, no por ello dejan de presentar reparos. Su objetivo era enjuiciar a los criminales de guerra japoneses conformándose para ello un tribunal con representantes de potencias aliadas y neutrales como la India. Cabe destacar que este último votó por la absolución como un signo de paz. Asímismo, lo que es una clara manifestación de que estos procesos carecín de imparcialidad, es que se prohibió a los japoneses de que pudieran acusar a los FiEUU por las bombas atómicas sobre Hiroshima y Nagasaki, o a la URSS por la violación al acuerdo de neutralidad de 13 de abril de 1941. En definitiva, los aliados no sólo definicron los delitos sino también determinaron cuáles serian perseguidos. Cfr. DAVID, "Grotius repudiated...", p. 348-349; JIMÉNEZ DE AsÚ.., Trutculo..., p. 996 y ss.;

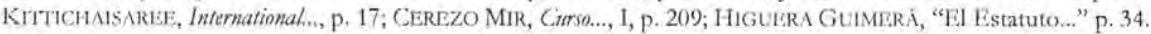

Cfr. CEREZO MIR, Curso..., I, p. 212; IESCHECK, "El Tribunal penal...", p. 54.
} 
3. A partir de entonces, las Naciones Unidas a través de la Comisión de Derecho Internacional (International Law Commision) comienza a trabajar en la elaboración de un Proyecto de Código de crímenes contra la paz y seguridad de la humanidad (Draft Code of Offences against the Peace and Security of the Mankind), en el cual debían recogerse los principios y tipos penales que fueron aplicados durante el juicio de Nuremberg. Si bien, existía el propósito de conformar una jurisdicción penal permanente - que se materializó en dos proyectos de $1951^{42}$ y 1953 -, la tarea quedó inconclusa debido a que no se llegó a un consenso sobre qué debía entenderse por agresión ${ }^{43}$. Sólo recién en 1974 la Asamblea General logra acordar un concepto, pero de alguna forma ya se había perdido el espíritu inícial y las motivaciones inspiradas en los juicios de Nuremberg para estructurar una Corte penal internacional fueron dejando paso a la resolución de los conflictos a través de los criterios propios de la Guerra Fría.

4. Si bien en 1991 la Comisión de Derecho Internacional aprobó como versión inicial un proyecto de Código de crímenes contra la paz y seguridad de la humanidad, no cabe duda que el impulso definitivo para terminar los trabajos que se habían iniciado sobre el proyecto de Código y la conformación de un Tribunal permanente viene dado por los trágicos sucesos de la ex Yugoslavia y Ruanda ${ }^{44}$. En efecto, por resoluciones del Consejo de Seguridad de las Naciones Unidas se establecieron Tribunales ad boc para el juzgamiento de quienes cometieron delitos de genocidio y otros atentados al Derecho humanitario dentro de los territorios de la antigua Yugoslavia - a partir del 1 de enero de $1991-^{45}$ y de Ruanda y Estados aledaños - entre el 1 de enero de 1994 y 31 de diciembre de $1994^{46}$. Pues bien, en 1994 se dio inicio a la segunda lectura del proyecto de Código, recogiendo los planteamientos que los gobiernos habían realizado a la versión preliminar expuesta

\footnotetext{
${ }^{42}$ Cfr. R. R. B., "The Municipal and International Law basis of Jurisdiction over War Crimes", en: British Year Book of International I aw, Vol. XXVIII, 1951, p. 382 y ss.

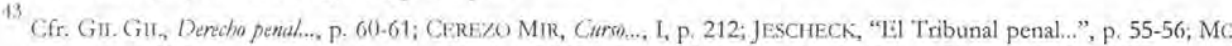
GolDRICK, "The permanent International Criminal Court: an end to the culture of impunity", en; Cnminal lan Reviem,

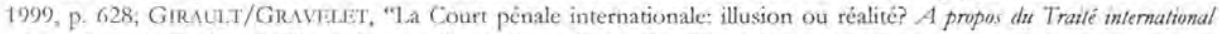
adopté à Rome le 17 juillet 1998", en: Retue de Science Criminelle et de Droil Pénal Comparí, 1999, p. 410-411.

44

Al respecto, efr. entre otros, CASSESEs, "Opinion: The International Criminal Tribunal for the Former Yugoslavia and Human Rights", en: European Human Rights Laj Rerien, 1997, p. 329 y ss. ; TIEILENBUN, "The paradox of International adjudication: developments in the International Criminal Court for the Former Yugoslavia and Rwanda, the World Court and the International Criminal Court", en: North Camlina Journal of International Lam and commenial regulation, $\mathrm{N}^{\circ} 3$. 2000 , p. 552 y ss.; ZAKR, "Analyse spécifique du crime de génocide dans le Tribunal pénal international pour le Rwanda", en: Retree de Science Criminelle et de Droit Penal Compar, 2001, p. 263 y ss.; Arozamena LASO, "El Tribunal penal internacional para la ex Yugoslavia", en: Actralidad Penal, 1997-2, p. 743 y ss. ; GIL GIL, "Tribunales penales...", p. $40 \mathrm{y}$ ss.

45

Resoluciòn 827 de 25 de mayo de 1993 del Consejo de Seguridad de las Naciones Unidas. 1 id. el texto del Estatuto en Whw derechos.org/nizkor/ley/yug,html

Resolución 955 de 8 de noviembre de 1994 del Conscjo de Seguridad de las Naciones Unidas, 1/id. el texto del Estatuto en www.derechos.org/nizkor/ley/ruanda.html
}

46 
en 1991, el que fue aprobado finalmente por la Comisión en $1996^{47}$. Cabe destacar que la Comisión de Derecho internacional también se propuso la elaboración de un Estatuto de Tribunal penal internacional, encomendándoselo en 1992 a un grupo de expertos, quienes finalizaron su misión en $1993^{48}$. Al año siguiente sobre la base del proyecto de Estatuto aprobado por la Comisión, la Asamblea General de las Naciones Unidas designó una Comisión ad boc. Dicho organismo preparó un informe, el que sirvió de base para que en 1995 la Asamblea General conformara un Comité preparatorio para el establecimiento de un Tribunal penal internacional (Preparatory Committee on the Establishment of an International Criminal Court) ${ }^{49}$. Este Comité celebró en total seis sesiones, siendo la última la de marzo-abril de 1998. Precisamente, el texto aprobado en esta última sesión sirvió de preparación a la Conferencia que habria de realizarse en Roma durante los meses de junio y julio de $1998^{50}$.

\section{d) Conformación del Tribunal Penal Internacional}

1. Es precisamente en Roma - reunión en la que participaron delegaciones de 160 Estados y más de 130 organizaciones no gubernamentales - donde se aprueba el texto definitivo del Estatuto del Tribunal Penal Internacional. Es importante resaltar que la Conferencia no estuvo exenta de conflictos, y no faltaron quienes dudaban que pudiera llegar a buen término, particularmente por la posición asumida por los Estados Unidos y China, dos miembros permanentes del Consejo de Seguridad de las Naciones Unidas. En efecto, desde un comienzo pudo apreciarse que las posiciones de los participantes se dividían esencialmente en dos conglomerados, a saber, los llamados "grupo de igual pensamiento" (Liked-Minded Group) que propugnaban por una Corte penal independiente y fuerte, en él podían encontrarse buena parte de los países de la Unión Europea y los latinoamericanos ${ }^{51}$.

\footnotetext{
${ }^{47}$ C.fr. Ambos, Justicia penal inlemacional, Ciudad de Guatemala, 2000), p. 33, quien analiza diversos ámbitos del proyecto de Código, tanto la versión de 1991 como la de 1996: LiROLA DELGadDo, "La competencia material...", p. 45 y ss. 48 penal internacional" (trad. Gil/Bruzzone), en: Lctmalidad penal, 1998-1, p. 225; GuTrerrez ESPADA, "Valoración critica de las criticas y temores suscitados por el Tribunal penal internacional (TPI) (Roma, 1998)", en: Hacia una justictu 51 internasional, Madrid, 2000, p. 558; JesCIIECK, "EI Tribunal penal...", p. 56.

Así, entre otros, Argentina, Australia, Canadá, Chile, Costa Rica, Dinamarca, Fspaña, Polonia, Reino Unido, Sudáfrica. Uruguay y Venezucla. Con respecto a los paises de la Unión Europea, debe considerarse el apoyo que el Parlamento Europeo, en sesión de 11 de marzo de 1997, manifestó a la 1dea de crear un Iribunal internacional 1Fid. ivww.derechos.org/nizkor/europa/parlamento/tpi.html Cfr. SALvioli, "¿Lia justicia que viene?, en: Agara, Renista de Ciencius Sociales, N², 1999, p. 174.
} 
Otra posición fue la asumida por buena parte de los integrantes del Consejo de Seguridad de las Naciones Unidas — aunque el Reino Unido adoptó una postura más cercana a la primera- quienes eran de la idea de un Tribunal con menores facultades y con mayores atribuciones dentro del Consejo ${ }^{52}$. Precisamente, la postura norteamericana fue una de las más duras, pues sostenía, por ejemplo, que la Corte sólo podía tener competencia en la medida que los Estados la aceptaran expresamente. Sólo la firme actitud asumida por los Estados Liked-Minded impidió su incorporación al Tratado, pues es claro que de haber sido aceptada esta propuesta, el futuro del Tribunal habría sido incierto ${ }^{53}$. En definitiva, después de largas sesiones, el 17 de julio de 1998, 120 estados votaron a favor del Estatuto, 7 lo hicieron en contra -EEUU, China, Libia, Irak, Israel, Qatar y Yemen-y hubo 21 abstenciones.

2. Empero, todavía quedaba un largo camino por recorrer para hacer realidad las normas contenidas en el Estatuto, pues de conformidad a lo que dispone el Art. 126, para su entrada en vigor era necesario la ratificación de 60 Estados. La tarea no era para nada fácil, y no pocos auguraban un rotundo fracaso dado el alto número de firmas que debían reunirse. Más aún considerando la importante influencia que podia ejercer EEUU, sobre todo a partir de la asunción de Bush en la presidencia, quien desde un primer momento mostró su absoluto rechazo a la instauración de un Tribunal penal internacional. A pesar de lo anterior, el día 11 de abril de 2002 se depositó en la Secretaría general de las Naciones Unidas el sexagésimo instrumento de ratificación, por lo que el Tribunal comenzó a funcionar el 1 de julio de 2002.

\section{TAREAS PENDIENTES PARA EL TRIBUNAL PENAL INTERNACIONAL}

1. La Asamblea de Estados Parte - Art. 112 del Estatuto- se abocó a la elección de los magistrados y del Fiscal. A este efecto se elaboró un procedimiento para la elección de éstos, tomando en consideración los requisitos contemplados en el Art. 36 del Estatuto. El período de nominación se cerró el 30 de noviembre de

\footnotetext{
${ }^{52}$ Cfr. Gutiúrerez EspadA, "Valonación crítica..." , p. 559.

No deja de llamar la atención las constantes presiones que ejerce el gobierno de EEUU para que los paises no ratifiquen el Estatuto de Roma, más aún sobre aquelles Estados en que el poder económico norteamericano se hace notar Aunque ya han transcurrido algunos años desde la aprobación del Estatuto, EEUU sigue empeñado en asumir el rol de garante de la seguridad mundial, despreciando la función que le cabe a los organismos internaciones - basta recordar st negativa a firmar el protocolo de Kioto y el Convenio para prohibir las minas antipersonales- La soberbia con que ha actuado en el conflicto de Irak es una clara manifestación de lo anterior. Para conocer la postura de FEUU, rid. la bibliografia citada en nota 5. Al respecto, AMBOS, Justicia penal.,. p. 66, es bastante críco con el papel de ELUU; "Esa actitud es lamentable, pero el funcionamiento de la Corte no depende de acciones militares internacionales, sino de la cooperación de los Estados parte, que como Estados del lugar de los hechos y de los sospechosos estarän obligados a entregar a éstos. Acciones militares internacionales serán necesarias sólo en el marco del capítulo VII CONU, para el mantenimiento de la paz incernacional. En esta situación, EEUU intentará utilizar, como en la Guerra del Golfo, tanto al Consejo de Seguridad de las NNUU como a la CPI para sus propios fines politicos".
} 
2002, respecto de los magistrados, y el 8 de diciembre del mismo año, para el Fiscal. Cabe señalar, que para la elección de magistrados se presentaron un total 45 candidatos $^{54}$, los que fueron elegidos por la Asamblea de Estados Parte entre el 3 y 7 de febrero de $2003^{55}$. En cuanto a la designación del Fiscal, ésta recayó en el argentino Luis Moreno Ocampo, elección que tuvo lugar el 21 de abril de $2003^{56}$. Como es sabido, Chile al no formar parte aún de esta instancia internacional, no pudo participar en estas trascendentales decisiones.

2. Cabe señalar además, que la Asamblea de Estados parte también debió hacerse cargo de los llamados Elementos del Crimen, conforme se dispone en el Art. 9 del Tratado. Es así, que estos elementos tendrán como "misión" ayudar a la Corte en la interpretación y aplicación de los Art. 6 al 8, esto es, los crímenes de genocidio, de lesa humanidad y de guerra. Se trata pues, de una fuente jurídica de vital importancia a la que puede recurrir la Corte en la resolución de los conflictos - sirve de apoyo interpretativo, no es vinculante para los magistrados-, como también puede apreciarse del propio tenor del Art. 21 del Estatuto. Me parece importante consignar que la Asamblea trabajó sobre la base de lo elaborado por la Comisión Preparatoria de la Corte Penal Internacional —entidad creada por la Resolución F adoptada durante la Conferencia de Roma de 1998-, a la que no sólo se le encomendó preparar un proyecto sobre los Elementos del Crimen, sino que además debió abocarse, entre otras materias, a las reglas de procedimiento y de prueba $^{57}$-Art. 51 del Estatuto- ${ }^{58}$. Esta Comisión celebró un total de diez sesiones, teniendo lugar la última de éstas entre los días 1 al 12 de julio de 2002. Pues bien, tal como lo afirma Ambos"), los elementos del crimen permiten la sistematización de los tipos penales contemplados en el Estatuto. Es del caso pues, que el trabajo de la Comisión preparatoria fue sometido a la Asamblea de Estados Parte, la que por consenso, en sesión celebrada el 9 de septiembre de 2002, lo aprobó ${ }^{60}$.

\footnotetext{
54 Ésta se puede conocer en www.un.org/law/icc/elections/judges/judges_nominations.htm

${ }^{55}$ Para los resultados de la clección, rid. htep://www.un.org/spanish/law/ice/clections/results/judges_results.htm

56 1 id. http://mww.un.org/spanish/law/icc/elections/results/prosecutor_results.htm

57

La resolución $\mathrm{f}$ estableció un mandato para la Comisión: el de elaborar proyectos de medidas prácticas para el estabiecimiento de la Corte y para que ésta entre en funciones. Entre otros proyectos, además de los ya mencionados: (a) Un acuerdo de rclación entre la Corte y las Naciones Unidas; (b) Principios básicos del acuerdo relativo a la sede que han de negociar la Corte y el pais anfitrión; (c) Reglamento Financiero y Reglamentaciòn Financiera Detallada; (d) Un acuerdo sobre los privilegios $\mathrm{e}$ inmunidades de la Corte; (e) Un presupuesto para el primer ejercicio financiero; ( $\mathrm{f}$ ) El reglamento de la Asamblea de los Estados Partes

58

Para mayor detalle, www.un.org/law/icc/prepcomm/prepfra.htm. Sobre esta materia, cfr. los diferentes articulos comprendidos en la Tercera Parte del libro Ambos (Coor.) La metra jisticia penal intemacional. Desarrollos PustRoma, Valencia, 2001

59

Cfr. AMBos, "Elementos del crimen' asi como Reglas de Procedimiento y Prueba de la Corte Penal Internacional", en: AMBOS (Coor.) La metra justicia penal internacional. Desarmollas Post-Roma, Valencia, 2001, p. 49-50.

60)

Vid. http://ods-dds-ny,un.org/doc/UNDOC/GEN/NO2/603/38/PDF/N(1260338.pdPOpenElement
} 
3. Sin entrar en mayores detalles, interesante es destacar que la Comisión antes de precisar los elementos de los delitos, expone, en una Introducción general, sus consideraciones en torno a una serie de principios, de manera que éstos sean aplicables a todos los crímenes. Es así, que en el párrafo 2 se hace referencia a cómo debe entenderse el elemento de la intencionalidad - Art. 30 del Estatuto-: "Como lo señala el artículo 30, salvo disposición en contrario una persona será penalmente responsable y podrá ser penada por un crimen de la competencia de la Corte únicamente si los elementos materiales del crimen se realizaron con intención y conocimiento. Cuando no se hace referencia en los elementos de los crímenes a un elemento de intencionalidad para una conducta, consecuencia o circunstancia indicada, se entenderá aplicable el elemento de intencionalidad que corresponda según el artículo 30, esto es, la intención, el conocimiento o ambos. A continuación se indican excepciones a la norma del artículo 30 sobre la base del Estatuto y con inclusión del derecho aplicable en virtud de las disposiciones del Estatuto en la materia."

4. En el caso del genocidio, el Art. 6 del Tratado de Roma distingue cuatro supuestos. Así, y a modo de ejemplo, tratándose del primero - 6 a) genocidio por matanza de miembros de grupo- se contienen los siguientes elementos: 1) que el autor haya dado muerte a una o varias personas; 2) que esas personas hayan pertenecido a un grupo nacional, étnico, racial o religioso determinado; 3) que el autor haya tenido la intención de destruir, total o parcialmente, ese grupo nacional, étnico, racial o religioso como tal; 4) que la conducta haya tenido lugar en el contexto de una pauta manifiesta de conducta similar dirigida contra ese grupo o haya podido por sí misma causar esa destrucción.

Cabe destacar que los elementos 3 y 4 recién citados también pueden encontrarse en los otros supuestos del delito de genocidio, lo que se explica si consideramos que se está frente a un delito de intención ${ }^{61}$ - tercer elemento-, así como es esencial considerar el contexto en que tales comportamientos se desarrollan - cuarto elemento-. Respecto de este último elemento de carácter contextual, a mi modo de ver es exigible que el sujeto conozca las existencias de estas circunstancias. En efecto, si se afirma que se está frente a un tipo incongruente por exceso subjetivo, para la consumación del delito es esencial que el sujeto realice actos que afecten a miembros de un determinado grupo, siempre que se enmarquen dentro de un plan dirigido a destruir éste. Es decir, por ejemplo, es posible estar frente al tipo que se examina con la muerte de una sola persona, siempre, claro está, que la intención sea la destrucción, total o parcial, del grupo al que pertenece la víctima. Se trata pues, de un delito de resultado cortado, por cuanto se requiere que el agente atente contra ciertos intereses individuales, no

${ }^{61}$ Asi, Gil. Gil, Deribo penal.., p. 178 y ss.; cfr, además, STEVEN, "Genocide and duty to extradite or procedure: Why the United States is in breach of its international obligations", en: Vinginia Journal of Intemational Law, 1999, p. 426 y ss. 
siendo necesario que el fin pretendido llegue a concretarse ${ }^{612}$. Es así, que en los casos Musema $^{63}$, Akayesu ${ }^{64}$ y Jelisic ${ }^{6.5}$ se señaló que para la configuración del tipo es necesario probar que el acusado ha tenido la intención específica de destruir, al menos en parte, determinados grupos en cuanto tales. Esto es, la víctima no es elegida por su identidad individual sino por pertenecer a ciertos grupos ${ }^{66}$.

5. En lo que respecta a los delitos contra la humanidad ${ }^{67}$, también la Comisión precisó sus "Elementos del crimen" y de manera particular respecto de las distintas modalidades comisivas que en él se comprenden. Por de pronto, no se exige para su configuración que se esté ante un conflicto armado ni es preciso un especial ánimo discriminatorio ${ }^{68}$. Para poder comprender esta figura es preciso determinar previamente qué debe entenderse por cometerlo como parte de un ataque generalizado o sistemático contra una población civil, como asimismo, cuál es el conocimiento que el agente debe tener de este ataque, es decir, si se requiere o no que tenga una noción acabada acerca de los planes o de la política que el Estado o la organización pretende llevar a cabo. Pues bien, en lo que se refiere al primer punto es importante afirmar que debe tratarse de actos que se hallan dentro de un ámbito, un contexto en que los ataques masivos o sistemáticos son organizados, dirigidos o al menos tolerados por el poder político. Al respecto, no debe olvidarse que uno de los componentes esenciales para esta clase de delitos dice relación con el manto de impunidad que los rodea. Es por ello que no todo ataque de estas características puede estimarse como delito contra la humanidad, aun cuando el autor esté motivado por razones étnicas o religiosas. En todo caso, lo anterior no supone que deba tratarse de políticas amparadas por el Estado, pues también esta figura que se está examinando se materializa en aquellos casos en que se está frente a organizaciones que controlan espacios territoriales.

6. Es preciso dejar claro que la exigencia de que se trate de un ataque generalizado o sistemático, constituyen requisitos alternativos, es decir, es posible

\footnotetext{
62

Cifr. FEljoo SANCIEZ, "Reflexiones en torno al delito de genocidio (artículo 607 del Código penal)", en: La I w, 19986, p. 2267 y ss: $Y$ es que, como señala buena parte de la doctrina, se trata de un delito que protege bienes juridicos supraindividuales, esto es, dererminados grupos humanos, constituidos como una unidad social. Para ello se deberá 3 texir a ciencias extrajuridicas, a fin de poder precisar cuando estamos frente a estas unidades.

(Saso Musema IClR-96-13 en: whwwictr.org/wwwroot/default.htm

Caso Akayesu ICTR-96-4 en: www.ictr.org/wwwroot/default.htm Caso Jelisic IT-95-10-A en: www.un.org/icty/judgement.htm

${ }^{66}$ Cfr. KrTICHAisARFF, International.., p. 72 y ss.; ZAKR, "Analyse specifique...", p. 263 y ss.

67 En cuanto al desarrollo y su evolución histórica, cfr. GIL GII., Dereche penal..., p. 106 y ss.

68

En todo caso, dentro de los crimenes de lesa humanidad se contempla la persceución de un grupo o colectividad con identidad propin fundada en motivos políticos, raciales, nacionales, étnicos, culturales, religiosos, de género u otros - Nrt. 7 1) h del Estatuto de Roma-. Pues aqui si debe el autor dirigir su conducta conforme a tales motivaciones. Lo mismo sucede con cl crimen de apartheid - Art. 7 1) i) del Esstatuto de Roma-, en que tambièn se requicre que el autor haya cometidos el delito en el contexto de un régimen institucionalizado de opresión y dominación sistemáticas de un grupo racial sobre uno o más grupos raciales.
} 
tomar en consideración cuestiones de orden cualitativo o cuantitativo para la configuración del delito ${ }^{69}$. En efecto, ya sea que se esté frente a un alto número de víctimas o cuando siendo irrelevante la cantidad de delitos cometidos se hallan unidos al formar parte de un ataque sistemático. Sin embargo, es esencial que en ambos casos — como se indica en el texto de elementos del crimen- se trate de ataques de naturaleza colectiva o de comisión múltiple dirigidos a una población civil. Asimismo, es fundamental exigir la presencia de una política concreta respecto a la cual puedan comprenderse los comportamientos individuales ${ }^{70}$. Justamente es aquí donde pueden presentarse las interrogantes en torno a las exigencias subjetivas, en cuanto a si el dolo del autor no sólo debe conocer el contexto de comisión el que se comprende el ataque, sino que además los detalles del plan o la política del Estado o de la organización. Es indudable que exigir esto último haría prácticamente imposible la configuración del delito, y asi se entendió al precisarse los elementos que se han de imponer a este crimen ${ }^{71}$. En consecuencia, es suficiente que el autor conozca que su comportamiento - cualquiera de las modalidades que se especifican en el Art. 7 del Estatuto de Roma- se comprende en un accionar más amplio, en el que se reúnen los presupuestos ya examinados ${ }^{72}$. Así, por ejemplo, tratándose de la primera forma comisiva constitutiva de crimen contra la humanidad que establece el Art. 7, a saber, el asesinato, se le exige al autor no sólo que el dolo comprenda la muerte de una o más personas, sino que además el autor haya tenido conocimiento de que la conducta era parte de un ataque generalizado o sistemático dirigido contra una población civil o haya tenido la intención de que la conducta fuera parte de un ataque de ese tipo.

7. En cuanto a los crímenes de guerra es indispensable distinguir diversos supuestos. En efecto, conforme se dispone en el Art. 8 del Estatuto de Roma, debe

\footnotetext{
69

Asi, cfr. QUEL LOPLZ, "Ia comperencia material de los tribunales penales internacionales: consideraciones sobre los crimenes tipificados", en: Creación de tma jirzidicioún penal internacional, Colección Escuela diplomática $\mathrm{N}^{\circ} 4$, Madrid, 200(), p. 91. Asimismo, Git. Gil., "Ios crímenes contra la humanidad y el genocidio en el Éstatuto de la Corte penal internacional a la luz de los Elementos de los Crimenes", en: AMBOs (Coor.) La mieta justicia penal internacional. Desamollos Past-Roma, Valencia, 2001, p. 81-82; CHESTERMAN, "An altogether different order defining the clements of crimes against humanity", cn: Duke foumal of Camparatite and Intemational Lan, Vol 10, 2000, p. 307 y ss.; MARTINEZ-CARDOS Ru17, "El concepto de crimenes de lesa humanidad", en: Actrulidal Penal, N ${ }^{\circ} 41,1999$, p. 778 y ss; LIROL_A DLLLado, "La competencia material...", p. 58-59.

70)

71

Iid. Caso Tadic II-94-1 en: www. un.org/icty/judgement.htm

"Los dos últimos elementos de cada crimen de lesa humanidad describen el contexto en que debe tener lugar la conducta. Esos elementos aclaran la participación requerida en un ataque generalizado o sistemático contra una población civil y el conocimiento de dicho ataque. No obstante, el último clemento no debe interpretarse en el sentido de que requiera prueba de que el autor tuviera conocimiento de todas las características del ataque ni de los detalles precisos del plan o la política del Éstado o la organización. En el caso de un ataque generalizado o sistemático contra una población civil que esté comenzando, la clăusula de intencionalidad del último clemento indica que ese elemento existe si el autor tenia la intención de cometer un ataque de esa indole".

72

Tal como afirma AMBOs, "Elementos del crimen'...", p. 52, debe prescindirse de un conocimiento de todas las caracteristicas de la agresión o de los detalles exactos de una política o de un plan. Este autor señala tambićn que cl dolo se pucde demostrar por la via de la prueba indiciaria cuando el autor únicamente queria favorecer una agresión extendida o sistemática.
} 
precisarse si se está o no frente a un conflicto armado internacional. Es por lo anterior que cuando se determinan los "Elementos del Crimen", se señala expresamente que tratándose de los apartados c) y e) del párrafo 2 del artículo 8 del Estatuto de Roma — supuestos de conflictos armados no internacionales - estarán sujetos a las limitaciones indicadas en los apartados d) y f) del mismo párrafo, que no pueden ser comprendidos como elementos de crimenes. En consecuencia, para que se puedan entender aplicables las disposiciones propias del Derecho Internacional humanitario ${ }^{73}$, es indispensable que exista un nexo suficiente entre el crimen que se alega y el conflicto armado ${ }^{74}$. Que así sea, esto es, que no se puedan comprender en esta esfera, tensiones, conflictos aislados, actos esporádicos de violencia, se debe a que la naturaleza del conflicto no supone que se esté frente a un quebrantamiento del Estado de Derecho. Por otra parte, es necesario consignar que si bien los Convenios de Ginebra no imponen para la configuración de los crímenes de guerra la sistematicidad o la masividad — como sí se exige respecto de los delitos de lesa humanidad, según se expuso supra-, lo anterior no resulta tan claro a la luz de las exigencias que dispone el Art. 8 del Estatuto ${ }^{75}$. En efecto, alli se establece que la Corte será competente respecto de los crímenes de guerra, cuando éstos se cometan como parte de un plan o política o como parte de la comisión en gran escala. Según Quel López ${ }^{76}$ esta confusa redacción se debió a una transacción con los EEUU que era partidario de establecer un umbral alto para la competencia del Tribunal, sin embargo para este autor, tal requisito es un cuerpo extraño al derecho humanitario bélico, que no ha sido incorporado como condición suplementaria, sino sólo como principio informador de la competencia de la Corte para casos especialmente importantes.

8. Uno de los aspectos más relevantes que impone esta clase de delitos es precisar el conocimiento que el autor debe tener del conflicto - teniendo en cuenta lo que establece el Art. 30 sobre elementos de intencionalidad-, es decir, si debe o no exigirse un conocimiento cierto acerca del carácter del conflicto ${ }^{77}$. Pues bien, en

Los Convenios de Gincbra, en el Art. 2 común, precisan qué debe entenderse por conflicto armado internacional: "Aparte de las disposiciones que deben entrax en vigor ya en tempo de paz, el presente Convenio se aplicani cn caso de guerra declarada o de cualquier otro conflicto armado que surja entre dos o varias Altas partes eontratantes, aunque una de ellas no haya reconocido el estado de guerra. El Convenio se aplicarí también en todos los casos de ocupación total o parcial del territorio de una Alta Parte Contratante, aunque tal ocupación militar no encuentre resistencia militar, $\mathrm{Si}$ una de las Potencias en conflicto no es parte en el presente Convenio, las Potencias que son parte en el mismo estarán, sin embargo, obligadas por él en sus relaciones reciprocas. Estarán, además, obligadas por el Convenio con respecto a dicha Potencta, si ésta acepta y aplica sus disposiciones". Por su parte, tratándose del Art. 8 2) a) que incrimina aquellos actos
} 
este punto la Comisión ha sido clara, estableciendo que no debe imponerse al autor una evaluación en derecho acerca de la existencia de un conflicto armado ni de su carácter internacional o no internacional. Agrega además la Comisión: "En ese contexto, no se exige que el autor sea consciente de los hechos que hayan determinado que el conflicto tenga carácter internacional o no internacional. Únicamente se exige el conocimiento de las circunstancias de hecho que hayan determinado la existencia de un conflicto armado, implícito en las palabras thaya tenido lugar en el contexto de... y que haya estado relacionada con él' ". No se requiere pues, que el autor esté en conocimiento de todas las circunstancias de hecho que permitan afirmar que se está frente a un conflicto armado, eso si debe conocer el nexo que existe entre los actos que ejecuta y el conflicto armado, es decir, debe estar consciente de que se presentan ciertas circunstancias de hecho que permiten establecer la existencia de un conflicto armado ${ }^{78}$. En todo caso, no se requiere que el acto sea ejecutado en el mismo lugar donde tienen lugar las hostilidades, pero sí que se enmarque dentro del conflicto armado ${ }^{79}$.

9. Por último, una de las tareas más importantes a las que deben abocarse las instituciones de la Corte penal internacional es a la definición del crimen de agresión, toda vez que de conformidad al Estatuto de Roma - Art. 5. 2. - también se ejercerá competencia sobre este delito ${ }^{80}$. Sin embargo, como dicha disposición se encarga de precisar, no sólo es esencial determinar qué se entenderá por agresión, sino que además se deberá procurar compatibilizarla con las funciones que le caben al Consejo de Seguridad. En efecto, el propio Art. 5. 2. señala que esta norma deberá ser compatible con las disposiciones correspondientes de la Carta de las Naciones Unidas. En este sentido debe tenerse presente lo que establece el Art. 39 de dicha Carta, en cuanto a que el Consejo de Seguridad es el llamado a calificar un acto de agresión. Es por ello que el deber que asume no parece nada fácil, no sólo por las discrepancias que se pueden presentar a la hora de precisar qué es el delito de agresión, sino también por la particular injerencia que puede tener el Consejo de Seguridad en el funcionamiento del Tribunal — vid. Art. 13 b) - Basta pensar en las consecuencias que pudietan manifestarse por la falta de pronunciamiento del Consejo. Ello podría generar que la competencia del Tribunal sobre el delito de agresión sea meramente simbólica. Por tanto, es indispensable buscar fórmulas que permitan evitar lo anterior. Precisamente, una de las técnicas que se han planteado

que se dirijan en contra de las personas o bienes protegidos por el Convenio de Ginebra, deben tenerse en cuenta diversas disposiciones contenidas en dichos Convenios, asi entre otros, los Art. 13, 24, 25 y 26 del Convenio 1 ; Art. 13 , 36, 37 del Convenio II; Art. 4 del Convenio IIl y Art. 4, 13 y 20 del Convenio IV.

78

Cfr. DORMANN, "Crímenes de guerm en los 'Elementos de los crimenes'”, en: A.MBOS (Coor.) La mueta justicia penal internacional. Dexamollos Post-Roma, Valencia, 2001, p. 113-118.

79

80

1si, Casos Tadic TT-94-1y Mucic et al, TT-96-21en: www.un.org/icty/judgement.htm

Para eonocer los documentos sobre el delito de agresión que se han presentado en la diversas sesiones de la Comisión preparatoria, wid. http://www.un.org/spanish/law/icc/documents/aggression/aggressiondocs.html 
es la de otorgarle un plazo al Consejo para que este organismo se pronuncie sobre un determinado hecho y si éste puede estimarse como agresión, lo que permitiría pues, iniciar la investigación. Si transcurre un plazo razonable — no más allá de doce meses - sin que el Consejo se pronuncie al respecto, el Tribunal estará habilitado para continuar con la investigación. Todo ello sin perjuicio de la facultad de que dispone el Consejo de conformidad con el Art. 16 del Estatuto de Roma ${ }^{81}$.

10. Cuando se discuten los elementos de la agresión, generalmente éstas se centran sobre la base de dos posiciones, a saber, si deben enfatizarse los actos del Estado o en cambio, centrarse de manera importante en la responsabilidad individual, como se desprende de los Estatutos de Nuremberg y Tokio. Es del caso, que el proyecto de Código de Crímenes contra la paz y la seguridad de la humanidad de 1996, al definir, en su Art. 16, el delito de agresión ${ }^{82}$, sigue esta segunda postura, esto es, que el objeto de persecución es la responsabilidad individual. Ahora bien, es indudable que se requiere que se trate de personas que dispongan del necesario grado de autoridad que les permita adoptar un rol decisivo y determinante en la agresión. Asimismo, es esencial para fundamentar la responsabilidad individual que ésta vaya unida a que la agresión sea llevada a cabo por un Estado. En consecuencia, sólo es un Estado, violando las leyes internacionales, el que puede realizar la agresión, bajo la decisión de determinados individuos que con la necesaria autoridad y poder, la inician. Se requiere pues, como requisito esencial para castigar por el delito de agresión, que un Estado haya violado las leyes internacionales.

\section{CONSIDERACIONES FINALES}

1. Uno de los grandes discursos del siglo $\mathrm{XX}$ ha sido el reconocimiento de los Derecho fundamentales y con ello el surgimiento de determinados deberes de proteción, lo que se pone de manifiesto no sólo a través de instrumentos internacionales - como lo son los que se comprenden dentro del Derecho Internacional Humanitario y el Derecho Internacional de los Derechos Humanos, sino que también los propios Estados los han recogido en sus ordenamientos jurídicos - esencialmente a través de las Constituciones Políticas-. Pues bien, desde el momento que en la esfera internacional se asume que no sólo existe la necesidad de un reconocimiento de los Derecho Humanos, sino también un deber de protección efectiva de éstos, va surgiendo la idea de que dichos deberes deben dirigirse hacia una vía punitiva, es decir, emanan de los instrumentos internacionales mandatos de punición, los que deben ser recogidos en los

\footnotetext{
81

82

Cfr, QUEL LOPEz, "La competencia material de los tribunales....", p. 103-104.

2 "IEl que, en cuantes dirigente u organizador, participe, activamente en la planificación, preparación, desencadenamiento o libramiento de una agresión cometida por un Estado, u ordene estas acciones, será responsable de un crimen de agresión". 1 id. el texro del proyectn de Codigo en wwww, un.arg/law/ilc/texts/dcodefra.htm
} 
ordenamientos nacionales. Precisamente, en este orden, podría afirmarse que el establecimiento de un Tribunal Penal Internacional constituiría la culminación de esta función punitiva que se manifiesta en el orden internacional.

2. Considerando pues, que el Tribunal Penal Internacional depende en buena medida de la actuación que desarrollen los propios Estados nacionales - basta pensar en la etapa investigativa-, es trascendental detenerse a reflexionar cómo éstos habrán de incorporar en sus ordenamientos internos las normas de derecho sustantivo contenidas en el propio Estatuto de Roma. Hay que consignar con respecto a esto último, que una inadecuada recepción permitiria la actuación de la Corte internacional de conformidad al principio de complementariedad, contenido en el propio Estatuto - Preámbulo, Art. 1,17-.

3. Frente a tales mandatos de punición que imponen los instrumentos internacionales los Estados deben, por una parte, tener en consideración los principios consagrados en sus propios ordenamientos - asi, el de legalidad, culpabilidad-, y por la otra, la obligación de incorporar las normas internacionales. Es aquí donde pueden surgir algunos problemas, no fáciles de dilucidar. Así, v. gr., ¿se puede imponer tal mandato de punición si éste excede criterios que permitan resolver si una conducta es o no merecedora de reproche penal y que se hallan fuertemente arraigados en sus respectivas tradiciones jurídicas? Parece que no, sobre todo si se tiene en cuenta que no pocas convenciones internacionales distan de los estándares deseables para las legislaciones nacionales. Siendo así, es dable afirmar, para así brindar una correcta interpretación a tales deberes de punición, que es preferible entenderlos — siguiendo a Bascuñán Rodríguez - ya sea como deberes de incriminación $\mathrm{o}$, en su caso, como deberes moderados de tipificación ${ }^{83}$. En efecto, de esta forma se le brinda al legislador el necesario grado de autonomía, sin que con ello pueda valorarse tal actuación como un incumplimiento a los mandatos internacionales de punición. Asimismo permite no vulnerar principios básicos limitadores de la actividad legislativa, como son los de legalidad y culpabilidad ${ }^{84}$.

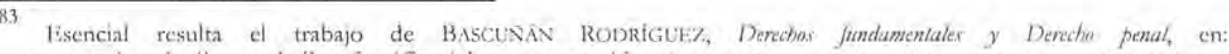
www.yalc.edu/lawweb/lawfac/fiss/sbascunan.pdf, quien señala que de los deberes de protección (deberes dirígidos a los Estados para que dispensen protección — no sólo respeto- a ciertos intereses) se pueden derivar mandatos de punición (deberes dirigidos a los Estados para que impongan una pena a los actos de afectación a los intereses que deben proteger). Pues bien, los deberes de punición pueden ser simples o cualificados. $A$ los simples Bascuñán los llama deberes de incriminación, que exigen una congruencia a nivel de las normas, lo que no significa que debe haber una congruencia en el nivel de las disposiciones. Bs decir, el acto constitutivo de delito debe ser reconocible como ámbito de referencia del supuesto de hecho de la norma punitiva interna. Por su parte, los deberes cualificados los denomina deberes de tífificación, los que a su vez pueden ser de dos clases: deberes moderados de tipificación y deberes extremos de tipificación. Respecto de los primeros - moderados-el Estado debe configurar un supuesto de hecho sistemáticamente autónomo, que razonablemente debe incluir una denominación individualizada congruente con el fin de protección del deber de punición. En cuanto al deber extremo, impone al Estado la transcripción en el derecho interno de al menos uno de los enunciados normativos ya fijados convencionalmente.

84

Tales problemas también se presentan en el proceso integracionista de la Unión Europea, sobre todo si se tiene en cuenta que buena parte de la normativa curopea adolece de un deficil democrifico. Si bien nadie puede poner en duda que el Derecho comunitarie tiene una clara injerencia en los ordenamientos penales nacionales - tanto en mandatos de
} 
4. $\Lambda$ fin de poder clarificar lo expuesto, resulta esencial remitimos a algunas normas del propio Estatuto de Roma, de manera particular aquellas que precisan los delitos respecto de los cuales el Tribunal penal internacional es competente. Es así, por ejemplo, que el Art. 7 1. j) que se refiere al crimen de apartheid-definido en el Art. 7 2. h) ${ }^{85}$ - presenta serios reparos desde la perspectiva del principio de taxatividad. Aún más grave, desde esta vertiente, es lo que acontece con lo dispuesto en la letra k) del Art. 7. 1. ${ }^{86}$. Particularmente llamativo es lo que sucede con el delito de desaparición forzada de personas, que se halla en el Art. 7. 1. i) y definido en el Art. 7.2. i) ${ }^{87}$, pues tal como se encuentra regulada vulnera principios básicos, incluso reconocidos por el propio Estatuto y en otras convenciones internacionales, como son los derechos a no autoincriminarse y a guardar silencio — vid. Art. 55 1. a) y 55. 2. b) del propio Estatuto- ${ }^{88}$. Es decir, se establece como condición para fundamentar la punibilidad, la negativa a informar sobre la privación de libertad o a dar información. La circunstancia de que el imputado ejerza un derecho que el propio Estatuto le reconoce, se estima, por otro lado, como fundamento para su culpabilidad ${ }^{89}, 5$. En definitiva, si bien me parece que el Tribunal penal internacional merece todo el respaldo de la comunidad de naciones, ello no impide actuar con cuidado, no sólo por el riesgo de que se puedan flexibilizar principios garantísticos básicos, sino también porque puede ser el comienzo de un desarrollo del Derecho penal internacional que puede significar la absorción de áreas que vayan más allá de lo que es la vulneración de los Derechos fundamentales más básicos — basta pensar en el medio ambiente o en el tráfico de drogas-, lo que indudablemente constituye

5. En definitiva, si bien me parece que el Tribunal penal internacional merece todo el respaldo de la comunidad de naciones, ello no impide actuar con cuidado, no sólo por el riesgo de que se puedan flexibilizar principios garantísticos básicos, sino también porque puede ser el comienzo de un desarrollo del Derecho penal internacional que puede significar la absorción de áreas que vayan más allá de lo

incriminación como de desincriminación- el problema se presenta en la determinación de las técnicas para llevar a 85 cabo tal recepción. Cfr. Carnevali Rodriguez, Derciho penal..., p. 257 y ss.

"Por 'cl crimen de apartheid' se entenderán los actos inhumanos de carácter similar a los mencionados en el pairrafo 1 cometidos en el contexto de un régimen institucionalizado de opresión y dominación sistemáticas de un grupo racial 86 sobre uno o más grupos raciales y con la intención de mantener ese régimen".

"Otros actos inhumanos de carácter similar que causen intencionalmente grandes sufrimientos o atenten gravemente contra la integridad fisica o la salud mental o fisica".

87

"Por 'desaparición forzada de personas' se entendera la aprehensión, la detención o el secuestro de personas por un Estado o una órganización politica, o con autorización, apoyo o aquiescencia, seguido de la negativa a informar sobre la privación de libertad o dar información sobre la suerte o el paradero de esas personas, con la intención de dejarlas fuera del amparo de la ley por un periodo prolongado".

88

Iil. además el Art. 14 del Pacto Internacional de Derechos Civiles y Politicos.

89 Al respecto, cfr, con detalle, MEDiN $\Lambda$ Scrullz, La desaparición forzada de personas como forma calificada de detención ilegal cometida por funcionario público, Memoria de grado, Universidad de Chile, 20)01, p. 61 y ss. 
que es la vulneración de los Derechos fundamentales más básicos — basta pensar en el medio ambiente o en el tráfico de drogas-, lo que indudablemente constituye un serio peligro, pues puede ser el comienzo de un recorrido expansivo similar al que actualmente siguen los sistemas penales nacionales. 